Por isso, a introdução de novas tecnologias no meio educacional, nem sempre tem correspondido às expectativas criadas.

É fundamental, para uma ótima apropriação das TCIs na criação e implementação de projetos em $\mathrm{EaD}$ (BAYMA, 2005), além do interesse e criatividade, um grupo engajado de professores capacitados e especialistas de diferentes áreas de conhecimento para atuar nestes novos espaços educativos.

A utilização de TCIs em EaD semipresencial é praticada na Universidade Federal de Itajubá, UNIFEI, e este artigo passa a relatar a análise e o resultado de um estudo de caso, pesquisa em mestrado em Engenharia de Produção, que apontam para um relativo nível de efetividade do processo ensino-aprendizagem nessa modalidade de ensino, segundo as experiências dos alunos e professores da universidade acima citada.

\section{A Educação a Distância}

O Decreto 5.622 que regulamenta a Educação a Distância (EaD) no Brasil caracteriza a modalidade de educação à distância como modalidade educacional na qual a mediação didático-pedagógica nos processos de ensino e aprendizagem ocorre com a utilização de meios e tecnologias de informação e comunicação, com estudantes e professores desenvolvendo atividades educativas em lugares ou tempos diversos (BRASIL, 2006).

Esse novo caminho concreto para o aprender, criado pela tecnologia, vem mudar as relações de ensino: o professor deixa de ser o único elo entre o aluno e o conhecimento, permite a expansão das fronteiras dos saberes, aumenta, diversifica e possibilita novas formas de relacionamento entre as pessoas. Segundo Cortelazzo (2002), essa tecnologia permite ainda o desenvolvimento das capacidades cognitivas, sensoriais e criativas do aluno.

Considerada durante muito tempo como estepe na educação, a EaD era utilizada quando modalidades tradicionais de ensino falhavam, vinha como solução aos economicamente desfavorecidos ou àquela parcela excluída do sistema educacional convencional. Rocha e Costa Neto (2001) consideram que a sociedade competitiva já compreende sua importância. Já se percebe o quanto pode ser vantajosa e eficiente como proposta de educação e/ou treinamento.

Portela, (2005) acredita que

"deve-se evitar uma posição antagônica da apologia cega dos avanços tecnológicos e resistência nostálgica em nome do tradicional",

pois é necessário sair do convencional, sepultar o improdutivo, entender que as dificuldades teórico- práticas a serem enfrentadas serão muito menores que os ganhos advindos.

\subsection{Educação a Distância e a educação formal na Universidade Federal de Itajubá}

Em Engenharia de Produção, o processo formal e tradicional de ensino-aprendizagem é baseado em interações entre professores e alunos, em um mesmo espaço e tempo. Diferentemente, a Educação a Distância, superando a distância física, resolve problemas com relação a local e a horários, e traz evidências de que pode ser uma ferramenta de extrema importância no processo (MONTEVECHI; COUTINHO; MOLINA, 2005).

Na Universidade Federal de Itajubá - UNIFEI, nem todos os professores do Instituto de Engenharia de Produção estão envolvidos com essa modalidade de ensino. Alguns utilizam ferramentas do ambiente virtual de aprendizagem (AVA) como enriquecimento ao ensino presencial, mas quem a experienciou de forma efetiva considera a EaD uma ferramenta importante no ensino dos conteúdos de Engenharia de Produção, com ganhos de qualidade comprovados (MONTEVECHI; COUTINHO; MOLINA, 2005).

A Portaria do MEC $n^{\circ} 4.059$ de 10 de dezembro de 2004 limita, no Brasil, em 20\% dos cursos presenciais os a distância, enquanto em outros países não existe um limite legal (MORAN, 2005). Na graduação em Engenharia de Produção-UNIFEI, disciplinas na modalidade semipresencial, em EaD, são ofertadas a partir do $3^{\circ}$ ano. As atividades a distância da universidade são decididas pelo caminho chamado de "Voluntarismo", que, ainda em Moran (2005), significa deixar o professor livre para definir o quanto essas atividades virtuais devem ser integradas às presenciais, o que acontece com frequência nas universidades públicas pela dificuldade de modificação nos projetos pedagógicos e onde as iniciativas individuais para transformação estão mais presentes que as institucionais, ou seja, utiliza aquele professor realmente interessado na modalidade de ensino em questão. Também na pós-graduação são ministradas disciplinas semipresenciais.

$\mathrm{O}$ ambiente de suporte virtual para ensino e aprendizagem a distância, o "TelEduc" - (projeto desenvolvido pelo Núcleo de Informática Aplicada à Educação (Nied) da Universidade Estadual de Campinas-SP) é o mais adotado pelos professores da universidade. Segundo esses, possui características como a facilidade de uso por pessoas não especialistas em computação.

A Universidade, na figura de seus professores, reconhece a importância da busca pela renovação de métodos de ensino que permitam ao aluno, de forma confortável, a assimilação e acomodação 
constante de saberes, porém temores e anseios, pelas dificuldades em conduzir o processo em $\mathrm{EaD}$, podem ser observados; existe a consciência e a preocupação com a falta de domínio técnico-pedagógico.

\section{Estudo de caso}

Baseado em Best, (1972), apud Lakatos e Marconi, (1999), considerando seus objetivos, a pesquisa é descritiva, pois aborda aspectos como a descrição, o registro, a análise e a interpretação de fenômenos atuais, objetivando seu funcionamento no presente.

Entendendo o processo de educação como uma das variedades das relações humanas, a pesquisa recaiu no campo social e com abordagem quali-quantitativa. Segundo Marques (2004), a pesquisa qualitativa em Educação mostra a forma de compreensão dos significados apresentados pelos entrevistados; realça valores, opiniões, atitudes, diagnosticando para o pesquisador a compreensão dos fenômenos caracterizados por alto grau de complexidade. Já a abordagem quantitativa traz à tona indicadores observáveis possibilitando quantificá-los, o que colabora para a melhor compreensão dos fatos.

Para Marques (2004), existem críticas quanto aos seus critérios de cientificidade, critérios esses descritos por Demo (Demo apud Marques 2004):

- Coerência - discurso logicamente construído

- Consistência - qualidade argumentativa do discurso

- Originalidade - contribuição do conhecimento

- Objetivação - abordagem teórico-metodológica de aproximação da realidade

Marques (2004) discute também outro critério de cientificidade, nesse caso externo, a intersubjetividade, ou seja, "a ingerência da opinião dominante dos cientistas de determinada época e lugar de demarcação científica".

Quanto ao procedimento técnico, o estudo de caso se apresentou mais adequado. YIN (2005) coloca que o estudo de caso é uma investigação empírica que pesquisa um fenômeno contemporâneo, em seu contexto real, principalmente quando os limites entre eles, fenômeno e contexto, não são claros. Baseia-se em várias fontes de evidências.

Para a consecução dos objetivos propostos, ou seja, avaliar a utilização/possibilidades da Educação a Distância no ensino de Engenharia de Produção, deu-se início à pesquisa diante das seguintes questões:

- A instituição de ensino, aqui representada por professores e alunos, estará disposta à quebra de paradigma, já que tão habituadas ao processo tradicional de ensino?

- Sabe-se que o desenvolvimento de projetos em $\mathrm{EaD}$ e a criação de cursos/ disciplinas nesta modalidade de ensino e aprendizagem dependem, fundamentalmente, do quanto os professores estão abertos à utilização/capacitação dessa tecnologia no processo ensino-aprendizagem. Existe na Universidade tal interesse?

- Essa modalidade de educação atende às necessidades dos alunos? Quais as impressões sobre esse método de ensino? Qual o olhar sobre o processo ensino-aprendizagem?

Não é pretensão da pesquisa ser conclusiva ou dada a generalizações. Segundo Lakatos (1999), sabe-se que a pesquisa é um procedimento formal, científico e se constitui num caminho para se conhecer ou descobrir verdades parciais.

Segue a explicitação do caminho percorrido, os instrumentos utilizados na coleta de dados como análise documental, questionário e entrevista semiestruturada, além do cenário e sujeitos da pesquisa, a saber: professores e alunos de uma Universidade Federal.

\subsection{Cenário e sujeitos da pesquisa}

Foi iniciada a investigação tendo a Universidade Federal de Itajubá/MG - UNIFEI agora caracterizada como cenário. Fundada em 23 de novembro de 1913 com o nome de Instituto Eletrotécnico e Mecânico de Itajubá - IEMI, foi a décima Escola de Engenharia a se instalar no País. Desde então vem destacando-se na formação de profissionais especializados.

Concretizou seu projeto de transformação em universidade em 24 de abril de 2002, com a sanção da lei número 10.435 pelo ex-presidente da República Fernando Henrique Cardoso (UNIVERSIDADE FEDERAL DE ITAJUBÁ, 2006).

Caracterizado o cenário, passou-se a investigar os sujeitos da pesquisa: professores e alunos dos cursos de graduação e pós-graduação em Engenharia de Produção da Universidade Federal de Itajubá. A Engenharia de Produção foi escolhida pela sua interface com a área de Humanas e também por alguns de seus professores demonstrarem grande interesse quanto a pesquisas em $\mathrm{EaD}$.

A Engenharia de Produção, no segundo semestre de 2006, contava com 165 alunos distribuídos em classes nos cinco (5) anos de graduação, dos quais $120(82,1 \%)$ participaram da pesquisa respondendo ao questionário proposto. A faixa etária destes alunos variava entre 18 e 25 anos, sendo a maior porcentagem do sexo masculino $(69,60 \%)$.

No curso de pós-graduação, Mestrado em Engenharia de Produção encontravam-se matriculados 91 alunos egressos de vários estados brasileiros e de diferentes formações. Dos alunos, 75,8\% eram do sexo masculino e a faixa etária variava entre 24 e 56 anos, com maior concentração na faixa de 30 a 40 anos (48\%), seguida das de 40 a 50 (23\%), de 20 a $30(19 \%)$ e de 50 a 56 anos (10\%). Dos 91 alunos matriculados (100\%), no $2^{\circ}$ semestre de 2006, 71 
(78,02\%) participaram da pesquisa, respondendo o mesmo questionário aplicado à graduação.

O Quadro 1 foi distribuído aos alunos em período de aula ou por $e$-mails.

Envolveram questões que permitissem análises quanto às expectativas, vantagens e limitações, e a própria visão do aluno quanto à efetividade do processo ensino-aprendizagem por meio da EaD.

A entrevista semiestruturada foi realizada com 25 $(80,64 \%)$ dos 31 professores, sujeitos da pesquisa, dos cursos de graduação e pós-graduação em Engenharia de Produção na Universidade Federal de Itajubá - UNIFEI, entre os meses de junho a setembro de 2006.

Decidiu-se por questões que propiciassem ao professor momentos de reflexão sobre sua concepção de $\mathrm{EaD}$, observação da sua prática, identificação, questionamentos, sua percepção a partir da aprendizagem por meio da $\mathrm{EaD}$ e, principalmente, interesse e disponibilidade, pois, para Palloff e Pratt (2002), como estimular nossos alunos a um processo transformador se nós não quisermos passar por ele?

\section{Apresentação e discussão dos resultados}

\subsection{Dos sujeitos professores da Universidade Federal de Itajubá}

A educação como processo formal e organizado para desenvolvimento humano, apresenta-se, historicamente, de maneira dual e paradoxal. Dual por constituir-se como conservadora, relutante quanto às modificações; e paradoxal por compreender a necessidade de renovação, promover o novo e o criativo (STANO, 2004).
Os comentários da entrevista semiestruturada com professores gravada, transcrita e analisada, sobre a utilização da $\mathrm{EaD}$ na universidade, permitem análises sob várias perspectivas, exploram o consenso e as divergências. Docentes falam dos seus sentimentos e das suas inquietações.

Concepções acerca de $\mathrm{EaD}$ apresentadas pelos professores demonstram resistência, insegurança ao novo como, "ainda tenho muitas dúvidas quanto à EaD..." (M) ou "acho que não temos ainda todo o recurso e informação para tratar disso do jeito que vejo muitas pessoas tratando..." (R), "só a EaD não supre as necessidades dos professores em termos de interação. A maioria dos professores não está preparada para trabalhar com essa metodologia de ensino" (A) ou ainda, "vejo a EaD somente como instrumento pedagógico" (D). Ao mesmo tempo percebem que se faz necessário um repensar sobre uma Pedagogia que não se cristalize, que busque, diante das importantes mudanças impostas pela revolução digital em diferentes contextos socioculturais, o atendimento às necessidades humanas, necessidades estas impostas pela própria história do desenvolvimento da humanidade. Novas propostas conceituais, novas tecnologias, novas possibilidades da prática do ensinar: "Acredito que nos próximos anos certamente vou utilizar essa ferramenta" (C).

Com relação às vantagens diagnosticadas na pesquisa, o professor J identifica sua prática: "tenho utilizado a EaD como forma complementar ao ensino presencial. Uma forma de preparar material e melhorar a recepção de conteúdos de assuntos complexos em engenharia".

Grandes reclamações das escolas e universidades são de que os alunos não aguentam mais a forma tradicional das aulas apresentadas: entediados reclamam

Quadro 1. Questionário distribuído aos alunos (Graduação e Pós-Graduação em Engenharia de Produção da UNIFEI e Curso Superior de Tecnologia: Gestão Empreendedora de Negócios da FATEC) em período de aula ou através e-mails.

Suas experiências com EaD superaram as expectativas?

( ) $\operatorname{sim}$ ( ) não

Você entendeu o meio utilizado como o mais adequado?

( ) $\operatorname{sim}$ ( ) não

Dentre as dificuldades, quais as mais encontradas:

a) deficiência/ complexidade no ambiente virtual?

b) metodologia não adequada?

c) dificuldade na interação com colegas/professores?

d) outros.

O que considerou positivo:

a) Utilização do ambiente virtual?

b) Interação, estabelecimento de parcerias e cooperação (entre os colegas e o professor)?

c) Facilidade para pesquisas?

d) Metodologia utilizada?

e) Motivação?

f) Outros.

Como você colocaria o processo ensino-aprendizagem por meio da Educação a Distância, considerando sua efetividade:

( ) ótimo ( ) bom ( ) regular ( ) sem opinião formada ( ) ruim 
de ouvir os professores falando horas e horas em sua frente, da rigidez, dos horários e da distância entre o conteúdo das aulas e suas vidas (MORAN, 2004). Na maioria das vezes, quando a tecnologia é utilizada na escola, tem por objetivo, único, ilustrar o conteúdo a ser trabalhado, e não criar desafios didáticos - ela vem como um verniz de modernidade.

Percebe-se na pesquisa o interesse de alguns professores à busca da eficiência e democratização do ensinar em EaD. Existe preocupação com a criação e desenvolvimento de materiais instrucionais. Luta-se contra as limitações da universidade no que se refere à própria tecnologia: "tamanho do vídeo, por exemplo. Temos muitos problemas com isso para ter uso eficiente. Temos pessoas ajudando, mas é preciso gente que conheça, para nos orientar (J)".

Procura-se o desenvolvimento de uma EaD com qualidade, a exigência de uma equipe multidisciplinar capacitada para construção e aplicação do curso/ disciplina, o que, além de atender às necessidades nos processos de aprendizagem dos alunos, traduz-se em possibilidades de aperfeiçoamento do próprio docente.

Existe na universidade certa inquietação com o atual incentivo financeiro do governo em projetos em $\mathrm{EaD}$ - "a EaD cresceu muito depois desse evento" $(\mathrm{R})$ ou "uma política educacional exclusivamente voltada para a EaD... Acho perigosíssimo. Dá a impressão de que o governo procurou um caminho aparentemente barato para investir na educação" (D).

A EaD traz essa conotação pejorativa de baixo custo, facilidade, curso por correspondência, especialmente para o leigo ou para aqueles que a conhecem pouco, o que é uma inverdade. Daí a grande preocupação e ansiedade dos docentes interessados, quanto à necessária qualificação: "o pioneirismo sem o devido cuidado pode se voltar contra nós" (D). A universidade deve primar por essa capacitação e por uma equipe especializada realmente integrada e competente, para que os cursos que sejam oferecidos fortaleçam o nome da instituição.

Outra percepção relevante é quanto ao interesse do aluno. Sabe-se que nem todos os recursos oferecidos pelas tecnologias são aproveitados ou utilizados de forma adequada, o que poderia se considerar uma limitação. O aluno ainda não está acostumado a esse tipo de solução. Muitos não se dedicam. "Às vezes o aluno já não trabalha no conteúdo presencial, mas você está lá, percebendo, recebendo o feedback, já com a EaD, fica meio fora de controle.." (J). O próprio professor tem dificuldades em conduzir o processo, ainda lhe falta o domínio técnico-pedagógico. Porém, na universidade, o retorno tem sido favorável, "experiência excelente. Pude comparar estratégias pedagógicas desestimulantes com estratégias pedagógicas estimulantes e motivadoras" (E), ou ainda "os alunos tem a facilidade de entrar, consultar, enviar perguntas. Às vezes, a quantidade de perguntas é tão grande no desenrolar do processo, que o trabalho do professor passa a ser redobrado. No presencial, quando o aluno considera a pergunta insipiente acaba não fazendo. Agora na EaD o aluno se expõe mais" (J.N.).

$\mathrm{O}$ desconhecimento quanto às possibilidades das TCIs em EaD pode ser um fator de influência em parte das posturas, temores e resistência percebidos nas respostas dadas pelos professores. A maioria dos profissionais em educação, ainda não tem a proficiência do uso das TCIs. Não sabe como usá-las como instrumento de trabalho ou instrumento de mediação nas relações (CORTELAZZO, 2000). A experiência, a busca do próprio crescimento pessoal e profissional por meio de pesquisas e exercício permanente em $\mathrm{EaD}$ certamente se concretizará na construção de conhecimento.

\subsection{A visão dos sujeitos alunos da Universidade Federal de Itajubá}

Os questionários, distribuídos para a graduação e pós-graduação, recolhidos e analisados, envolveram questões quanto às expectativas, vantagens e limitações, e a própria visão do aluno quanto à efetividade do processo ensino-aprendizagem por meio da $\mathrm{EaD}$. A análise aponta para um nível considerável de eficácia do processo aprendizagem e será apresentada.

Quanto ao atendimento às expectativas, Figuras 1 e 2, iniciais, tanto para os alunos da graduação $(67,85 \%)$ quanto para os alunos da pós-graduação $(65,40 \%)$, verificou-se que essa modalidade de educação atendeu-os de forma satisfatória. Para muitos, um computador antes usado somente para entretenimento agora se transforma numa ferramenta para o aprender.

Essa utilização muda o relacionamento entre o grupo aprendente, entre professores e alunos, com o processo de aprendizagem e até mesmo com a máquina. Palloff e Pratt (2002) apontam em experiências no California Institute of Integrated Studies, na John F. Kennedy University e na Ottawa University que quando os alunos se envolvem num processo de aprender utilizando tecnologias, como o computador, eles não aprendem só o conteúdo sobre o curso ou disciplina, mas sobre o seu processo de aprendizagem e sobre si mesmo. A questão deixa de ser "o que aprendi sobre essa matéria" para "o que é necessário para entendê-la". O processo de aprendizagem passa a envolver a autorreflexão sobre o conhecimento adquirido.

Quanto ao meio utilizado, Figuras 3 e 4, tem-se um resultado significativo de satisfação. Os respondentes, graduação $(69,36 \%)$ e pós-graduação $(78,40 \%)$ consideram positiva a utilização de tecnologias. $\mathrm{O}$ temor de que as tecnologias possam adicionar um grau de complexidade maior ao processo, afetando 
a capacidade de absorção dos alunos, parece não ocorrer em grande escala (STEIL; BARCIA, 2006). Os alunos percebem, e reconhecem a necessidade de acompanhamento à renovação e busca de novos modelos para o aprender.

A tecnologia provoca, instiga, leva o aluno a pesquisas e à construção de conhecimentos. No ambiente on-line, o papel do professor torna-se o de um facilitador, animador, organizador que conduz seu aluno a explorar não só o conteúdo do curso ou disciplina, mas materiais a eles relacionados, sem restrições.

Nas Figuras 5 e 6, em dificuldades, a interação teve maior relevância: para Steil e Barcia, (2006), a interação é entendida como ação recíproca entre dois ou mais indivíduos, que pode ser presencial ou mediada por alguma tecnologia, e a importância desta, na EaD, é reconhecida como meio de aumento de desempenho ou da satisfação pelo aprendizado. No entanto, segundo os dados obtidos, a interação como dificuldade no ambiente representa uma média considerável no resultado $(38,70 \%$ graduação e $41 \%$ pós-graduação).

Para Landim, (1997), considerando a interatividade como o fenômeno elementar das relações humanas, nas quais as educativas estão presentes, seus pressupostos não são comumente abordados. Interatividade por si só, em relações comuns e ou universais, é suficientemente complexa para exigir fundamentos sociológicos, psicológicos, linguísticos, semióticos, históricos e antropológicos. A interatividade depende da cultura do grupo.

Em EaD a interação não se dá apenas entre o aluno e o instrumento mediador, mas com todos os elementos do grupo, considerando individualmente história de vida, família, trabalho. A autora afirma que a distância em $\mathrm{EaD}$ não sugere somente o espaço físico, mas o social, o emocional, o psicológico, o cultural, o filosófico, entre outros.

Atendimento às expectativas graduação

$67,85 \%$

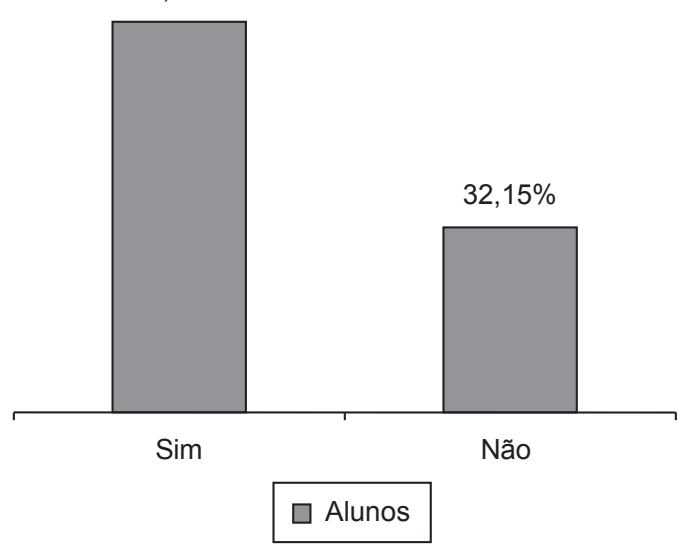

Figura 1. Resultado da opinião dos alunos da graduação quanto ao atendimento às expectativas sobre a $\mathrm{EaD}$ para efetividade do processo ensino-aprendizagem.
A sala de aprendizagem virtual, da maneira como se apresenta hoje traz professores e alunos representados por textos numa tela. Tanto os professores quanto os alunos ficam como que desencarnados (PALLOFF; PRATT, 2002). Esse é um dos motivos que leva à dificuldade nas interações. Para alguns chega a uma situação de desconforto.

Estar atento à diversidade, às diferenças individuais é o mesmo que valorizá-las, estimula a criação de ideias, opiniões e a capacidade de aprender a aprender. Vários autores indicam que uma pessoa introvertida, pela ausência das pressões sociais presenciais tem melhor desempenho na aprendizagem mediada por tecnologias. O relativo anonimato faz com que ela desabroche, sinta-se mais à vontade. Em contrapartida, ainda para os mesmos autores, as pessoas extrovertidas podem encontrar dificuldades de se fazerem notar em um ambiente on-line, algo que fazem mais facilmente quando o contato é direto.

Professores e alunos devem ser capazes de lidar com o ambiente virtual de aprendizagem, ambiente este em que não se pode ouvir, ver ou tocar as pessoas com quem estão interagindo, cuidando inclusive para não adotar a postura de uma nova "persona" descrita por Palloff e Pratt (2002), ingressando em áreas desconhecidas de suas próprias personalidades.

A ética é ponto central na ação educativa. A boa interação requer respeito, atendimento, valorização não sob o formalismo do trato profissional, mas sob cordialidade, o que, sem dúvida, vai suscitar um comportamento recíproco.

Considerando-se que o processo de Educação a Distância se dá entre humanos, é preciso que todos estejam preparados para administrar conflitos, contradições e dilemas em qualquer fase do processo (LANDIN, 1997).

Atendimento às expectativas pós-graduação $65,40 \%$

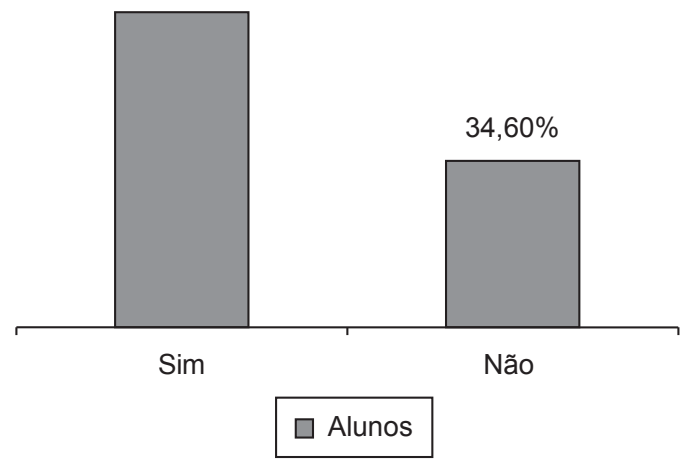

Figura 2. Resultado da opinião dos alunos da pós-graduação quanto ao atendimento às expectativas sobre a $\mathrm{EaD}$ para efetividade do processo ensino-aprendizagem. 
Meio adequado - graduação

$69,36 \%$

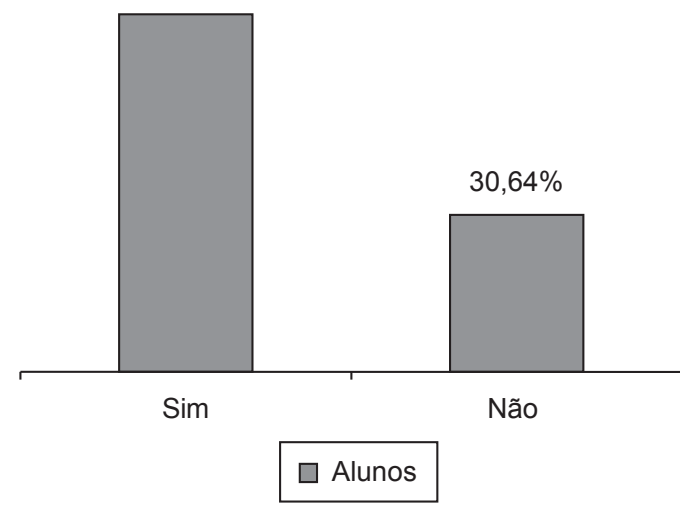

Figura 3. Resultado da opinião dos alunos da graduação quanto ao entendimento do meio ser adequado ao processo ensino-aprendizagem.

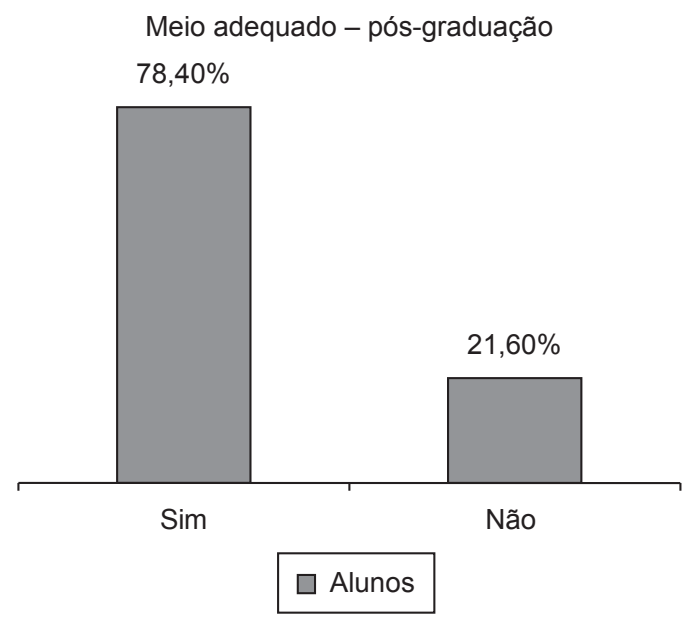

Figura 4. Resultado da opinião dos alunos da pós-graduação quanto ao entendimento do meio ser adequado ao processo ensino-aprendizagem.

Dificuldades encontradas - graduação

$45,16 \%$

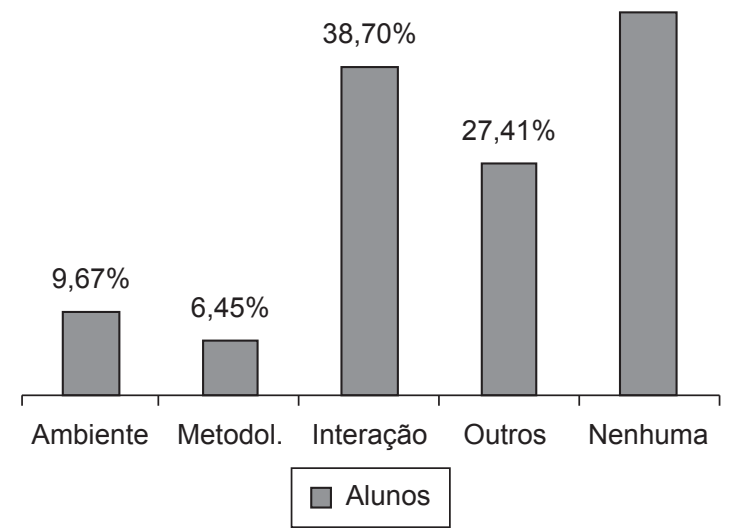

Figura 5. Resultado da opinião dos alunos da graduação com referência as dificuldades encontradas no ambiente para a efetividade do processo ensino-aprendizagem.
Dificuldades encontradas - pós-graduação

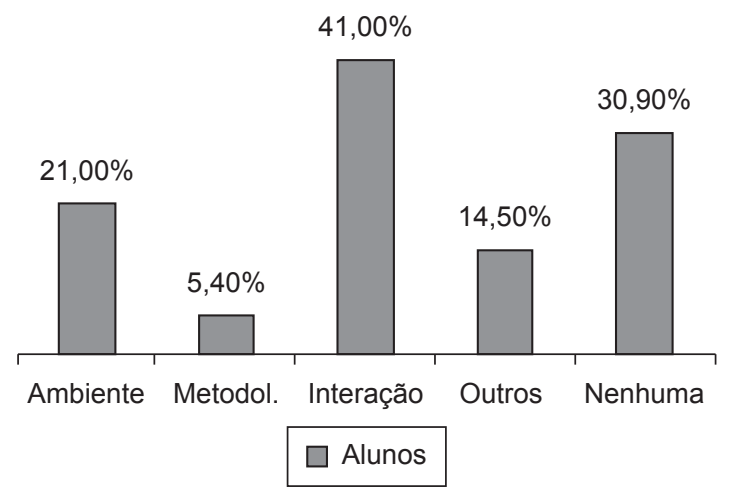

Figura 6. Resultado da opinião dos alunos da pós-graduação com referência as dificuldades encontradas no ambiente para a efetividade do processo ensino-aprendizagem.

Pontos positivos - graduação

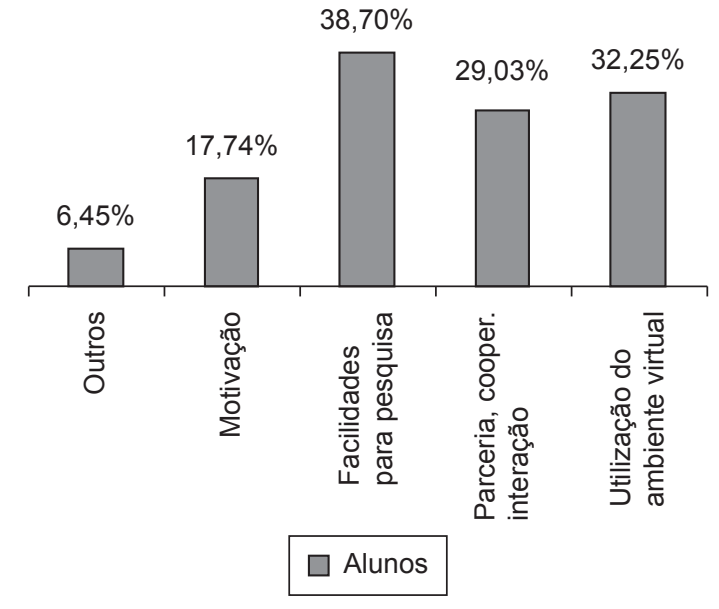

Figura 7. Resultado da opinião dos alunos da graduação com referência aos pontos positivos encontrados no ambiente para a efetividade do processo ensino-aprendizagem.

Pontos positivos - pós-graduação

$52,70 \%$

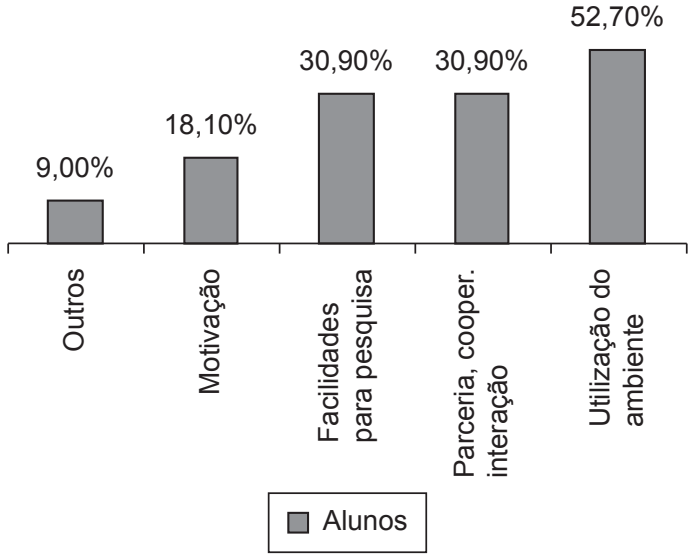

Figura 8. Resultado da opinião dos alunos da pós-graduação com referência aos pontos positivos encontrados no ambiente para a efetividade do processo ensino-aprendizagem. 
Da alternativa "nenhuma dificuldade", o maior percentual, $45,16 \%$, encontra-se no grupo de alunos da graduação em Engenharia de Produção. Esse dado pode estar relacionado à faixa etária dos alunos da graduação, da intimidade com que os jovens de hoje lidam com tecnologias, principalmente com o computador, instrumento utilizado na $\mathrm{EaD}$ da universidade.

O ambiente virtual de aprendizagem a distância adotado pela UNIFEI é o TelEduc. Possui um conjunto enxuto de funcionalidades diferenciando-o de outros ambientes para educação disponíveis no mercado. No caso da Universidade, aqueles que têm utilizado esse ambiente em cursos ou disciplinas sentem-se confortáveis nesse meio. As diferenças individuais de aprendizagem podem diagnosticar o quanto o aluno pode se encontrar apto a se ajustar nesta modalidade de ensino.

De acordo com as respostas dos sujeitos-alunos, nas Figuras 7 e 8 , os pontos positivos mais considerados foram a utilização do ambiente virtual $(32,25 \%$ graduação e 52,70\% pós-graduação) e a facilidade para pesquisas $(38,70 \%$ graduação e $30,90 \%$ pós-graduação): temos como vantagens além da rapidez da aquisição e disseminação do conhecimento, materiais didáticos mais dinâmicos e a flexibilidade de horário para dedicação ao curso ou disciplina.

$\mathrm{O}$ aluno tem condições de explorar profundamente o tema a ser estudado, intercambiar essas informações e desenvolver além da autonomia, elemento crucial e desejado pela EaD, motivação para aprender. Gadotti (2000) cita que, pela Internet, pode-se acessar inúmeras bibliotecas em diversas partes do mundo a partir de qualquer sala de aula. As novas tecnologias permitem acessar conhecimentos transmitidos por palavras, por imagens, sons, fotos, vídeos (hipermídia), etc. Atualmente a informação deixou de ser uma área ou especialidade para se tornar uma dimensão de

Efetividade do processo

ensino - aprendizagem graduação

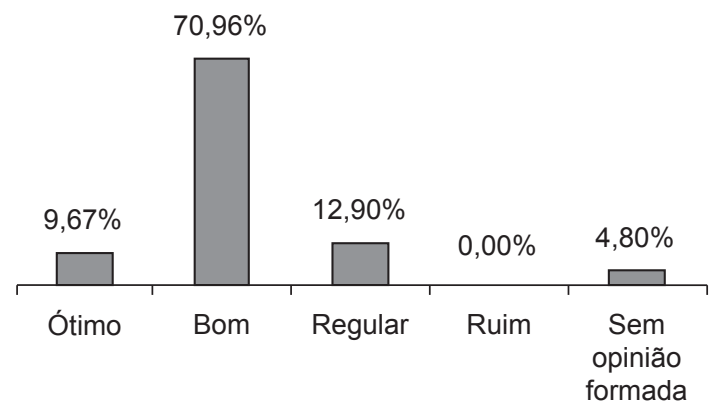

Alunos

Figura 9. Resultado da opinião dos alunos da graduação com referência a efetividade do processo ensino-aprendizagem por meio da $\mathrm{EaD}$. tudo, transformando profundamente a forma e a organização da sociedade.

Com referência à efetividade da aprendizagem, Figuras 9 e 10, pode-se notar que, segundo a visão dos alunos, graduação $(70,96 \%)$ e pós-graduação (70,90\%) o processo é considerado como "bom", confirmando que aspectos referentes ao uso da tecnologia não prejudicam o processo. É importante esclarecer que o perfil dos alunos questionados pela pesquisa parece de sujeitos que estão adaptados às TCIs, acostumados com as interações advinda delas, de forma social ou laboral, uma possibilidade provável de melhor utilização e aproveitamento da mídia.

Fica claro que a utilização da EaD com garantia de sucesso está relacionada ao modelo pedagógico e à estrutura de apoio utilizados. A EaD pode oferecer muitos recursos para o aluno, além das aulas expositivas, mas é a promoção de novas maneiras de ensinar e de solucionar problemas que pressupõe atitudes do professor como a criação e o desenvolvimento de metodologias e materiais adequados, desenvolvidos especialmente para essa modalidade de ensino, além da própria ligação do aluno com a máquina, que motiva sua participação nas propostas disponibilizadas com consequente aprendizagem. Tem-se a consciência de que tudo isso é muito novo, mas, ao longo do percurso, dependendo da vontade e do esforço empreendido, habilidades devem ser criadas e desenvolvidas.

É imprescindível que a universidade reflita sobre esse resultado, se a garantia da eficiência do processo pode ser comprovada, segundo a opinião dos alunos. A utilização da $\mathrm{EaD}$ deve continuar apoiada, incentivada em seu aprimoramento, pois novas formas de ensinar, se trabalhadas com competência, podem promover melhoria da qualidade do processo do "aprender".

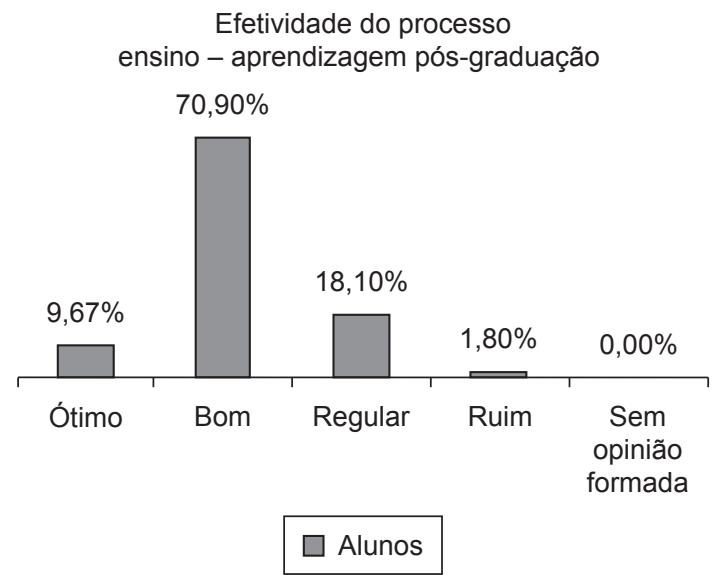

Figura 10. Resultado da opinião dos alunos da pós- graduação com referência a efetividade do processo ensinoaprendizagem por meio da $\mathrm{EaD}$. 


\section{A Faculdade de Tecnologia Internacional - uma instituição de Educação a Distância do Paraná}

A pesquisadora, no final da avaliação dos dados, compreendeu a necessidade de fomentar a reflexão sobre os resultados encontrados. Assim, buscou nova observação e investigação em uma instituição de ensino superior com estrutura e funcionamento de cursos a distância já consolidados. A princípio, havia o interesse em se fazer uma comparação entre as duas instituições de ensino, mas a avaliação dos dados obtidos contribuiu de forma diferente: sugeriu, diante da visão dos alunos, a efetividade da $\mathrm{EaD}$ quanto ao processo ensino-aprendizagem.

A instituição de ensino escolhida foi a FATEC (do grupo educacional UNINTER). Com sede em Curitiba, Paraná, com centros associados distribuídos em todos os estados do Brasil. A FATEC iniciou suas atividades com o objetivo de oportunizar à população jovem e adulta a formação acadêmica por meio de educação na modalidade a distância, semipresencial, oferecendo cursos Superiores de Tecnologia.

Opera com equipamentos de tecnologia digital via satélite, aulas ao vivo por videoconferência, permite interações síncronas com professores através da linha 0800 e assíncronas pelo portal ou e-mail, facilitando a comunicação entre a instituição e o aluno. Possui também material complementar impresso e tutoria presencial qualificada.

A pesquisa optou pelo curso Superior Tecnologia em Gestão Empreendedora de Negócios, nome adequado ao catálogo Nacional de Cursos Superiores de Tecnologia, antes Gestão de Negócios de Pequeno e Médio Porte, Portaria n ${ }^{\circ} .505$ D.O.U. 08/03/2004 - por possuir disciplinas afins aos cursos de graduação e pós-graduação em Engenharia de Produção.

Fica claro que a intenção da pesquisa não é a comparação das tecnologias utilizadas na UNIFEI

Atendimento às expectativas - FATEC $83,30 \%$

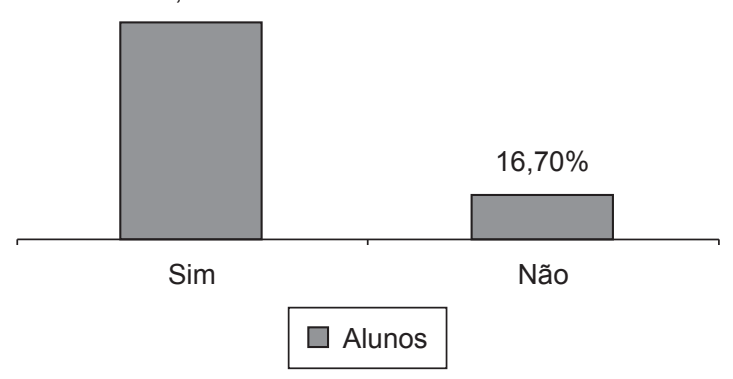

Figura 11. Resultado da opinião dos alunos da FATEC quanto ao atendimento às expectativas da $\mathrm{EaD}$ para efetividade do processo ensino-aprendizagem. ou FATEC, mas coletar dados para perceber as possibilidades da educação a distância, ou seja, entender e prover o desafio que é relacionar a tecnologia à metodologia adequada com a perspectiva de transformar informações recebidas em constante produção de saberes com destinação profissional, social e humanitária.

\subsection{Visão dos alunos Faculdade de Tecnologia - quanto à efetividade do processo ensino-aprendizagem em Educação a Distância}

A experiência neste novo contexto do aprender vem muitas vezes carregada de crenças pela própria falta de conhecimento do que seja a educação a distância. Alguns alunos estão menos predispostos a aprender ou mesmo, por diversos fatores, tais como pré-requisitos, habilidades, falta de familiaridade com a tecnologia, não estão aptos a uma aprendizagem não convencional. Porém, da opinião dos alunos $(83,30 \%)$, quanto ao atendimento das expectativas, conforme Figura 11, verifica-se que a $\mathrm{EaD}$ atendeu de forma satisfatória suas expectativas. Esse resultado sugere que, quando o interesse, talvez pela necessidade, e a motivação são despertados, objetivos são atingidos.

Os respondentes $(83,30 \%)$ consideram positivo o meio utilizado (Figura 12). Sentem-se confortáveis com o sistema de teleconferência, portal on-line e materiais impressos, além da tutoria presencial, disponibilizados pela instituição. Percebem na infraestrutura e suporte utilizados uma organização responsável.

Das dificuldades encontradas: a tecnologia de "teleconferência" contribui para a diminuição de dificuldades, já que somente o uso do computador, pela falta de acesso da maioria, poderia justificar um problema.

Dificuldades de interação, retratada na Figura 13, no entanto, está confirmada (33,30\%) como questão de

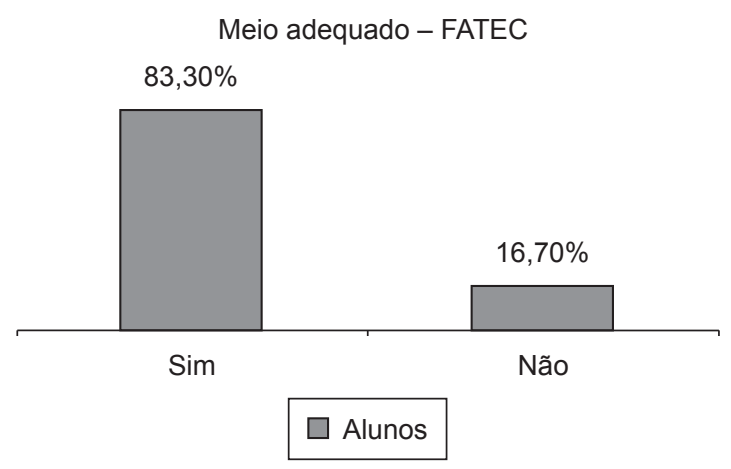

Figura 12. Resultado da opinião dos alunos da FATEC quanto ao entendimento do meio ser adequado ao processo ensino-aprendizagem. 
barreira ao aprendizado, e esta, em EaD, é imprescindível. Nota-se ainda a preferência em interações de contexto face a face. Cabe ressaltar que o professor, em $\mathrm{EaD}$, deverá deixar o aluno seguro sobre esse processo de aprender, que ainda é novo, mas acontece de forma efetiva quando existe uma maior interação.

O ambiente virtual $(48,10 \%)$ e facilidade para pesquisas $(14,80 \%)$, dos pontos positivos, Figura 14, são bastante considerados. Possibilidades de comunicação são ampliados pelas telas dos computadores a outros espaços de saberes.

As informações fluem de todos os lados e podem ser acessadas e trabalhadas por todos: professores, alunos e os que, pelos mais diferenciados motivos se encontram excluídos da escola e dos campi (KENSKI, 2005).

Foi constatada também como ponto positivo pelos próprios alunos, a cooperação e a motivação

Dificuldades encontradas - FATEC

$33,30 \%$

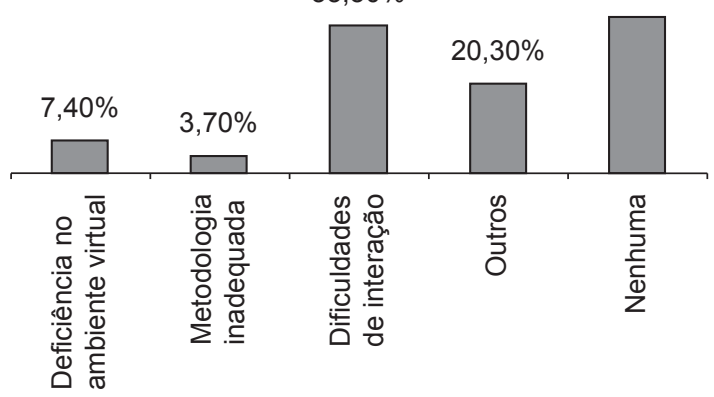

Alunos

Figura 13. Resultado da opinião dos alunos da FATEC com referência as dificuldades encontradas no ambiente para a efetividade do processo ensino-aprendizagem.

Pontos positivos - FATEC

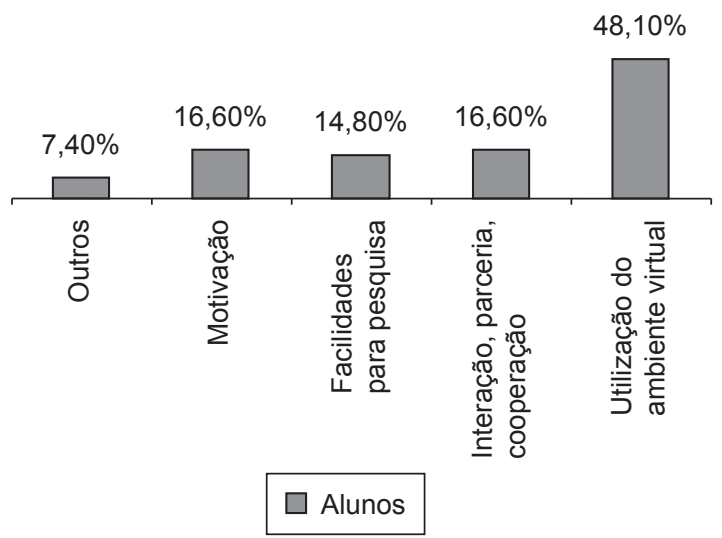

Figura 14.Resultado da opinião dos alunos da FATEC com referência aos pontos positivos encontrados no ambiente para a efetividade do processo ensino-aprendizagem.
$(16,60 \%)$ para melhora do processo de aprendizagem. Desenvolve habilidades para trabalhos em equipes, produção coletiva, diferentemente da competição que estão acostumados a vivenciar.

$\mathrm{O}$ resultado, quanto à questão da eficiência do processo ensino-aprendizagem: a Figura 15 demonstra que a utilização em cursos/disciplinas da modalidade a distância é predominantemente positiva, $68,51 \%$ dos alunos classificam a eficiência do processo como "Bom".

Dessa análise pode-se considerar que a promoção de novas maneiras de ensinar e de solucionar problemas motiva os alunos à aprendizagem, mas é certo que a utilização da EaD está relacionada ao modelo pedagógico e à estrutura de apoio utilizados, o que garante aos alunos o sucesso. No entanto, é necessário o incentivo e a criação de metodologias estratégicas para o aumento da qualidade e aprimoramento da ação educativa.

\section{Avaliação do grau de concordância entre os alunos da Universidade Federal de Itajubá (graduação e pós-graduação) e Faculdade de Tecnologia quanto às possibilidades de utilização da Educação a Distância}

A reunião de todas as etapas da pesquisa com alunos da UNIFEI e FATEC se faz agora presente na avaliação do grau de concordância relacionado às possibilidades da $\mathrm{EaD}$ entre os alunos das instituições pesquisadas.

Uma análise estatística qualitativa que, partindo dos dados obtidos, pela medição da associação de variáveis numéricas e não numéricas, Smailes e McGrane (2006), traz identificações que permitem não só visualizar, diagnosticamente, a aceitação e a percepção do aluno com relação à efetividade do processo ensino-aprendizagem, mas o pensar de

\section{Eficiência do processo ensino-aprendizagem - FTI} $68,51 \%$

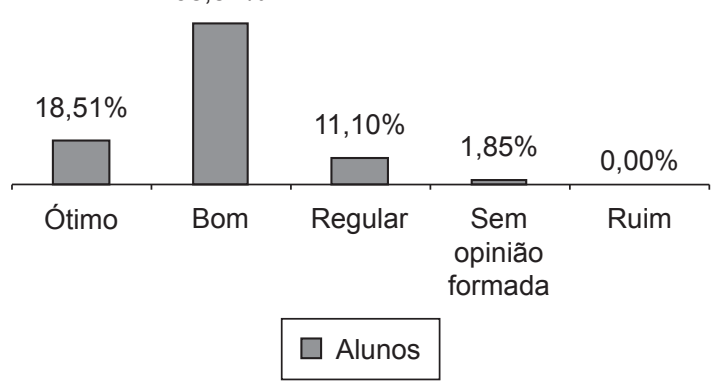

Figura 15. Resultado da opinião dos alunos da FATEC com referência a efetividade do processo ensino-aprendizagem por meio da $\mathrm{EaD}$. 
propostas metodológicas, diálogos e a necessidade emergente de novas práticas educacionais.

\subsection{Coeficiente de correlação ordenado de spearman}

Equação 1, sendo:

$$
r=1-\frac{6 \sum d^{2}}{n\left(n^{2}-1\right)}
$$

- $\mathrm{n}$ = número de pares de observações; e

- $\mathrm{d}=$ diferença entre a ordem de $\mathrm{x}$ e $\mathrm{y}$.

Do resultado de $\boldsymbol{r}$, (Quadro 1):

O gráfico apresentado na Figura 16 permitiu a visualização da concordância, bastante significativa, entre os sujeitos pesquisados nas questões ligadas ao atendimento das expectativas. A escala variou entre 66,4\% da pós-graduação UNIFEI, 67,9\% da graduação na UNIFEI e 83,3\% da FATEC. A porcentagem de maior importância corresponde à opinião dos alunos da FATEC. Muitos destes, tendem a acreditar na má qualidade e na facilidade de se concluir um curso a distância. Crenças que são revisadas e modificadas ao longo do processo, quando percebem o quanto o sucesso dessa capacitação vai depender do esforço e do interesse próprio: o aluno, contatando com os objetos que são disponibilizados no AVA (ambiente virutal de aprendizagem), elaborando as atividades propostas a seu tempo e de seu espaço, aprende por si mesmo. (ALMEIDA, 2003).

A concordância entre os alunos UNIFEI e FATEC no item: "meio adequado" também pode ser facilmente visualizado pelo gráfico na Figura 17. Diferentemente dos alunos da UNIFEI, nem todos os alunos da FATEC tem acesso fácil às tecnologias utilizadas pelos curso de gradução e pós-graduação da Universidade, mas percebem a importância e a necessidade da utilização desses meios, já que, possivelmente sem eles, suas chances de voltar à escola estariam bastante reduzidas. A tecnologia de videoconferência, ainda no caso da FATEC, proporciona um ambiente muito similar ao ensino presencial (STEIL; BARCIA 2006), o que facilita para muitos, e a própria instituição de ensino provê essa falta do aluno impossibilitado de aquisição de outras mídias.
Na Figura 18, das dificuldades encontradas, existe nível bastante razoável de similaridade entre as opiniões. Ambiente, dificuldade de interação e outros, considerado por muitos como a falta de diversidade nas atividades propostas, são as barreiras, para melhor efetividade do processo, mais perceptíveis pelos próprios alunos.

A Figura 19 indica pouca correlação entre os dados, ou seja, é a menor resposta ao grau de concordância entre os pesquisados. Atribuímos esse resultado às diversidades presentes como nível social, faixa etária, e a própria familiaridade com a tecnologia. Um ponto diagnosticado pela pesquisa como de grande importância para os alunos da FATEC, é quanto à motivação. As reações e as atitudes de alunos são fortemente afetadas por meio do aumento e da facilitação da interação (VALENTA et al. 2001) que pode ser proporcionada. Entendeu-se que a presença do tutor para orientação das atividades e acompanhamento pedagógico presencial é de grande ajuda ao processo. Outro fator seria a própria vontade de participar do mercado de trabalho ou da necessidade de constante aperfeiçoamento para manutenção deste.

Quanto à efetividade do processo ensinoaprendizagem, segundo avaliação dos alunos das instituições UNIFEI e FATEC, existe, pela Figura 20,

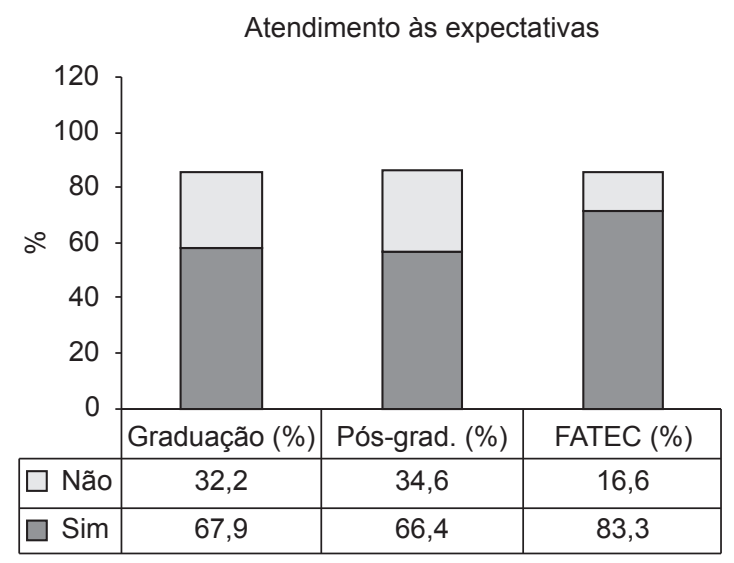

Figura 16. Concordância entre alunos da UNIFEI e FATEC quanto ao atendimento das expectativas.

Quadro 1. Coeficientes de correlação ordenada de Spearman. Fonte: Smiles e McGrane (2006).

\begin{tabular}{|l|l|}
\hline+1 & $\begin{array}{l}\text { Existe uma Correlação Positiva Perfeita entre os dados. (à medida que } \boldsymbol{x} \text { aumenta, } \boldsymbol{y} \text { aumenta). } \\
\text { Se } \boldsymbol{x} \text { for conhecido, } \boldsymbol{y} \text { pode ser previsto exatamente. }\end{array}$ \\
\hline $\mathbf{+ 0 , 8}$ até $\mathbf{+ 1}$ & Existe Forte Correlação Positiva entre os dados. (à medida que $\boldsymbol{x}$ aumenta, $\boldsymbol{y}$ aumenta). \\
\hline $\mathbf{+ 0 , 4}$ até $\mathbf{+ 0 , 8}$ & Existe Correlação Positiva Moderada entre os dados. (à medida que $\boldsymbol{x}$ aumenta, $\boldsymbol{y}$ aumenta). \\
\hline $\mathbf{- 0 , 4}$ até $\mathbf{+ 0 , 4}$ & Existe muito pouca Correlação entre os dados. \\
\hline $\mathbf{- 0 , 4}$ até $\mathbf{- 0 , 8}$ & Existe Correlação Negativa Moderada entre os dados.(à medida que $\boldsymbol{x}$ aumenta, $\boldsymbol{y}$ diminui). \\
\hline $\mathbf{- 0 , 8}$ até $\mathbf{- 0 , 1}$ & Existe Forte Correlação Negativa entre os dados. (à medida que $\boldsymbol{x}$ aumenta, $\boldsymbol{y}$ diminui). \\
\hline $\mathbf{- 1}$ & Existe uma Correlação Negativa Perfeita entre os dados.(à medida que $\boldsymbol{x}$ aumenta, $\boldsymbol{y}$ diminui). \\
\hline
\end{tabular}




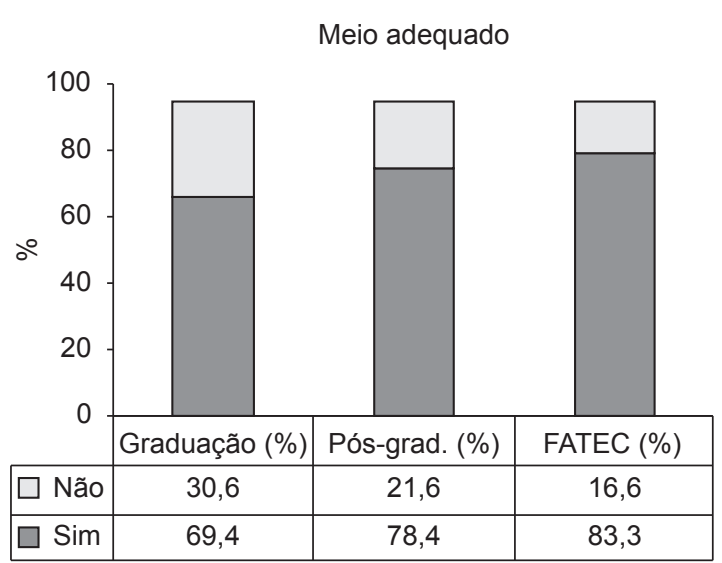

Figura 17. Concordância entre alunos da UNIFEI e FATEC quanto ao meio utilizado.

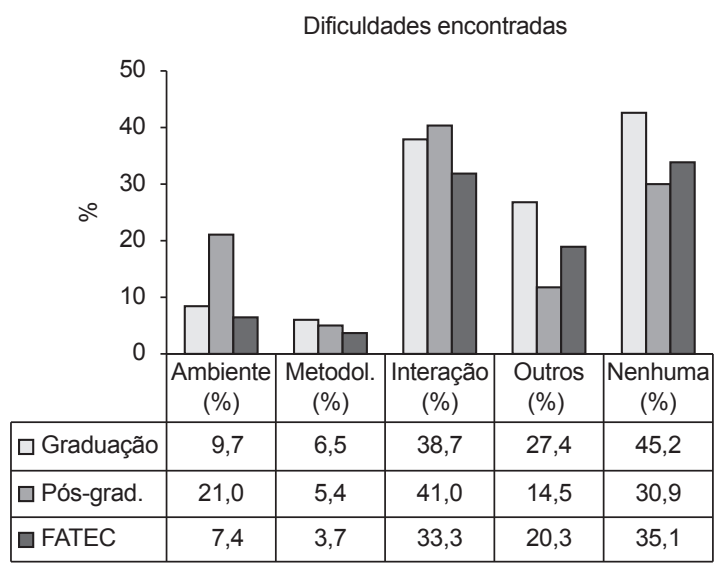

Figura 18. Concordância entre alunos da UNIFEI e FATEC quanto as dificuldades encontradas.

forte similaridade entre as variáveis e, portanto forte correlação positiva dos dados, um alto grau de concordância entre a opinião dos pesquisados. A satisfação dos alunos pesquisados quanto à efetividade dos seus cursos a distância validam os resultados identificados por Steil e Barcia em 2006, com alunos do curso de mestrado a distância também em Engenharia de Produção, numa instituição de ensino superior no Brasil.

\section{Considerações finais}

Sabe-se hoje que a educação pode ser promovida nos mais diferentes ambientes sociais. Educar, como disse Boff (2005), é fazer pensar. É tornar o homem consciente de si, dos seus deveres, dos seus direitos, é perceber que a colaboração e a parceria são fundamentais para o crescimento. É ir além do pessoal, refletindo e atingindo seu redor. É permitir

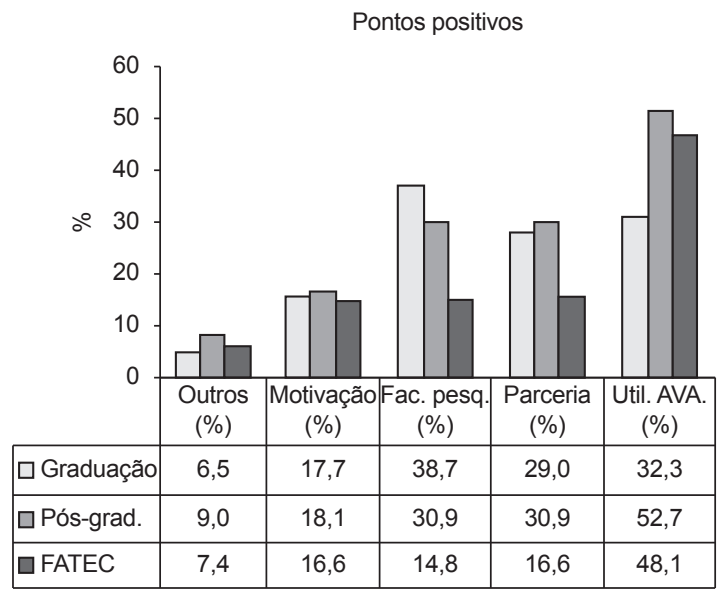

Figura 19. Concordância entre alunos da UNIFEI e FATEC quanto aos pontos positivos.

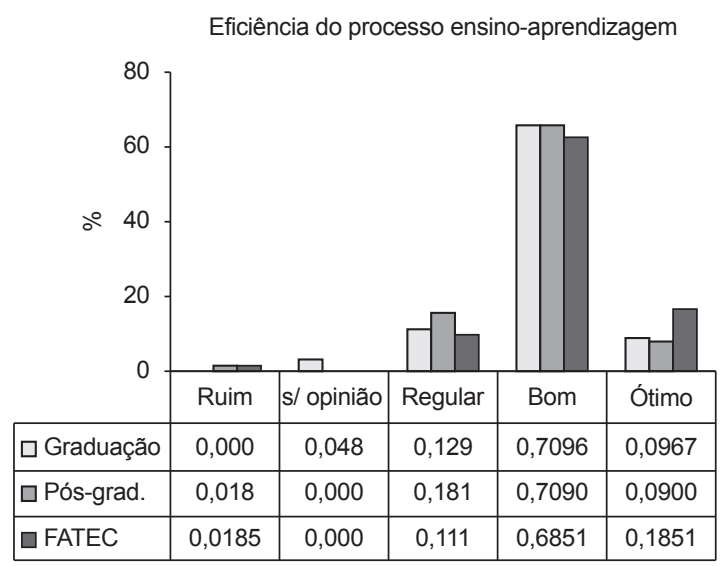

Figura 20. Concordância entre alunos da UNIFEI e FATEC quanto a efetividade do processo ensino-aprendizagem por meio da EaD.

o erro e o crescimento por meio dele, é revisar-se, alterar suas posições.

Para Kenski (2005), o pensamento das pessoas, quando conectadas, adquire novas feições. As formas de raciocinar, a imaginação criadora perseguem caminhos diferentes dos que habitualmente estamos acostumados. Entretanto, muitas instituições de ensino ainda são impermeáveis a estas mudanças que afetam tanto a estrutura da sociedade quanto atividades de trabalho ou de produção. E a escola continua se baseando na transmissão e difusão do conhecimento pela linguagem escrita, enquanto jovens, rodeados por estimuladores de sentido, recebem informações em diferentes linguagens, se veem diante de uma nova forma de aprender: aquela que se realiza observando, praticando, modificando, comprovando resultados. 
A reunião de todas as etapas da pesquisa com alunos da UNIFEI e FATEC, a partir da avaliação dos dados obtidos, traz identificações que podem contribuir não só para a formação do acadêmico, mas para o pensar de propostas metodológicas, diálogo e a necessidade emergente de novas práticas educacionais.

A entrevista semiestruturada mostra o professor, apesar de interessado, ainda inseguro quanto ao uso dessa modalidade de ensino. Seu conhecimento provém mais de experiências pessoais que de uma ação planejada e estruturada de capacitação. Concordam que são exigidas novas competências, postura, formas de interação que desenvolvidas acrescentarão à sua prática. Entendem a disposição de uma prática para experimentar, manusear tecnologias que permitam a invenção de realidades.

O questionário retrata um aluno familiarizado com a utilização de TCIs, entende sua importância e como estão revolucionando não só o processo de educação, mas também o processo de trabalho, o processo de acumulação capitalista e o processo de apropriação (LOUREIRO, 2005), portanto, propícia e adequada aos novos tempos. Capacita, universaliza, democratiza, socializa, supre a necessidade de atualização permanente do saber. Traduz-se em aprendizagens significativas e relevantes - fazem parte da escola, mas é necessário que sejam vistas como condição de ferramentas que propiciam ao aluno e ao professor o poder de serem atores do processo ensino-aprendizagem.

Concluindo, é imprescindível que a universidade reflita sobre o resultado. Se a garantia da eficiência do processo foi sugerida pela pesquisa, segundo a opinião dos alunos, a utilização da $\mathrm{EaD}$ deve continuar apoiada, incentivada em seu aprimoramento, pois, novas formas de ensinar, se trabalhadas com competência, podem promover melhoria da qualidade do processo do "aprender". A EaD, hoje, já é vista como um recurso capaz de possibilitar ao indivíduo a aprendizagem, a lidar com a questão da formação continuada, como estratégia para elevar a competitividade nacional, como necessária para o avanço de uma sociedade que pede por uma renovação pedagógica, levando ao indivíduo a aprendizagem para a vida toda. Se a realidade de nossa universidade caminha junto à tecnologia e, por esse motivo, é reconhecida internacionalmente, como insistir em práticas e relações convencionais de ensino?

Com o objetivo de criar um espaço de reflexão sobre os desafios e possibilidades impostos por essa modalidade de ensino, tenta-se, por meio das falas dos professores e dos alunos um repensar crítico com referência a EaD. Essa avaliação, mesmo que numa amostra pequena, pode levar a universidade a um ponto de partida para a melhoria e planejamento de atividades educacionais.

\section{Referências}

ALMEIDA, M. E. B. Distance learning on the internet: approaches and contributions from digital learning environments. Educação e Pesquisa, v. 29, n. 2, p. 327-340, 2003. Disponível em: <http://www.scielo. br/scielo.php?script $=$ sci_arttext\&pid=S1517-9702200 3000200010>. Acesso em: 15/10/2006.

BAYMA, F. Educação a Distância e Educação Corporativa. In: BAYMA, F. (Org.). Educação Corporativa: desenvolvendo e gerenciando competências. São Paulo: Prentice Hall, 2005.

BOFF, L. Desafios Humanísticos e éticos da educação a distância. In: BAYMA, F. (Org.). Educação Corporativa: desenvolvendo e gerenciando competências. São Paulo: Prentice Hall, 2005.

BRASIL. Ministério da Educação. Secretaria de Educação a Distância - SEED. Brasília, DF, (s.d.). Disponível em: <http://portal.mec.gov.br/seed/index.php?op tion $=$ content $\&$ task $=$ view $\& i d=61 \&$ Itemid $=190>$. Acesso em: 02/2006.

CORTELAZZO, I. B. C. Colaboração, Trabalho em Equipe e Novas Tecnologias de Comunicação: Relações de Proximidade em Cursos de Pós-Graduação. Tese de Doutorado, FE-USP, 2000.

GADOTTI, M. Perspectivas atuais da educação. São Paulo em Perspectiva, v. 14, n. 2, p. 3-11, apr./jun. 2000.

KENSKY, V. M. Comunidades de aprendizagem em direção a uma nova sociabilidade na educação. 2005. Disponível em: <http://firgoa.usc.es/drupal/node/23559>. Acesso em: 08/2006.

LAKATOS, E. M.; MARCONI, M. A. Técnicas de Pesquisa. 4 ed. São Paulo, SP: Atlas, 1999.

LANDIN, C. M. M. P. F. Educação a distância: algumas considerações. Rio de Janeiro, 1997. (Registro: Biblioteca Nacional, n. 128, livro 20, f. 13).

LOUREIRO, M. D. Desafios da Sociedade do Conhecimento Educação. In: BAYMA, F. (Org.). Educação Corporativa: desenvolvendo e gerenciando competências. São Paulo: Prentice Hall, 2005.

MARQUES, W. F. S. Pesquisa Qualitativa em educação: reflexões. 2004. Disponível em: <http://www. psicopedagogia.com.br/artigos/artigo.asp?entrID=592>. Acesso em: 15/06/2006.

MONTEVECHI, J. A. B.; COUTINHO, M. M. S. R.; MOLINA, C. E. C. Avaliação da eficácia no uso de material de ensino a distâncoa em disciplina de Pesquisa Operacional. In: SIMPÓSIO BRASILEIRO DE PESQUISA OPERACIONAL - SBPO, 37., 2005, Gramado, RGS. Anais...

MORAN, J. M.; ARAÚJO FILHO, M.; SIDERICOUDES, O. A ampliação dos vinte por cento a distância: estudo de caso da Faculdade Sumaré-SP. 2005. Disponível em: $<$ http://www.abed.org.br/congresso2005/por/pdf/172tcc3. pdf>. Acesso em: 02/01/2007.

MORAN, J. M. Propostas de mudanças nos cursos presenciais com educação on-line. In: CONGRESSO INTERNACIONAL DE EDUCAÇÃO A DISTÂNCIA, 11., 2006, Salvador, BA. Anais... [S.1.]: ABED, 2005. Disponível em: <www.abed.org.br/congresso2004/ por/gradetc.htm\#08>. Acesso em: 08/2006. 
UNIVERSIDADE ESTADUAL DE CAMPINAS UNICAMP. Núcleo de Informática Aplicada à Educação da Universidade Estadual de Campinas NIED. Campinas, SP, (s.d.). Disponível em: <www. nied.unicamp.br/>.

PALLOFF, R. M.; PRATT, K. Construindo comunidades de aprendizagem no ciberespaço. São Paulo: Artmed, 2002.

PORTELA, E. Educação, comunicação e saber. In: BAYMA, F. (Org.). Educação Corporativa: desenvolvendo e gerenciando competências. São Paulo: Prentice Hall, 2005.

ROCHA, A. A. E.; COSTA NETO, P. L. Educação continuada e a distancia em engenharia. Revista Ensino de Engenharia ABENGE, v. 20, n. 1, p. 1-7, 2001.

SMILES, J.; MCGRANE, A. Estatística Aplicada à Administração com Excel. São Paulo: Atlas, 2006.
STANO, R. C. M. T. Aproximações pedagógicas e Educação a Distância. In: WORKSHOP DE EAD, 1., 2004, Itajubá. Anais... Itajubá: Universidade Federal de Itajubá - UNIFEI, 2004.

STEIL, A. V.; BARCIA, R. M. Atitudes de alunos e professores com relação a cursos de mestrado em Engenharia de Produção a distância. Revista Gestão e Produção, v. 13, n. 1, p. 141-149, 2006.

Universidade Federal de Itajubá - UNIFEI. (s.d.). Disponível em: <www.unifei.edu.br>. Acesso em: 10/08/2006.

YIN, R. K. Estudo de caso: planejamento e métodos. 3 ed. Porto Alegre: Bookman, 2005.

VALENTA, A. et al. Identifying student attitudes and learning styles in distance education. Journal of Asynchronous Learning Networks, v. 5, n. 2, p. 111-127, 2001. 